Article

\title{
The Effect of Laser Power on the Interface Microstructure of a Laser Remelting Nano-SiC Modified Fe-Based Ni/WC Composite Coating
}

\author{
Yuncai Zhao *, Wen He, Huihui Du and Peng Luo \\ School of Mechanical and Electrical Engineering, Jiangxi University of Science and Technology, Ganzhou 341000, \\ China; jxhewen1225@163.com (W.H.); huihui_du0605@163.com (H.D.); gz177466786221@163.com (P.L.) \\ * Correspondence: 9120050091@jxust.edu.cn
}

Received: 4 July 2018; Accepted: 19 August 2018; Published: 22 August 2018

\begin{abstract}
The plasma sprayed Fe-based Ni/WC composite coating on the surface of 45 steel was post-treated by laser remelting with the addition of nano-SiC. The effect of laser power on the interface microstructure of a laser remelting nano-SiC modified Fe-based Ni/WC composite coatings were researched. The metallographic structure, microscopic morphology, phase composition, and microhardness of the remelted layer were visually analyzed by metallographic microscope, scanning electron microscope (SEM), X-ray diffractometer (XRD), and microhardness tester, respectively. The results showed that the nano-SiC modified remelted coating was smooth and compact, and with no fine cracks. The remelted layer was mainly composed of [ $\mathrm{Fe}, \mathrm{Ni}], \mathrm{Cr}, \mathrm{Fe}_{0.04} \mathrm{Ni}_{0.36}$ phase. The metal elements $\mathrm{Fe}, \mathrm{Ni}, \mathrm{Cr}$, and $\mathrm{Si}$, and non-metallic element $\mathrm{C}$, appeared to diffuse, and there was metallurgical bonding between the coating and the matrix. With the increase of laser power, the smaller the average grain size, the wider the half-peak height (FWHM), and the more obvious the grain refinement. When the laser power was $500 \mathrm{~W}$, the interface metallurgical showed the best effect. Furthermore, the nano-sized SiC particles served as the core of the heterogeneous nucleation to refine the grains on the one hand, and promoted the formation of a hard intermediate phase in the coating on the other hand. Therefore, the laser remelting and the addition of nano-SiC particles greatly improved the microhardness of the coating. The larger the laser power, the smaller the microstructure characteristics and the fewer the number of holes. With increasing laser power, the hardness increased in general terms and the maximum hardness increased by $51 \%$.
\end{abstract}

Keywords: plasmas praying; laser remelting; laser power; refinedgrain; nano-SiC

\section{Introduction}

As a key surface strengthening and protection method, thermal spraying technology has been widely used to prepare wear-resistant layers, corrosion-resistant layers, various functional coatings [1-3], and repair or remanufacture crankshafts, plungers, boilers, tubes, aircraft, ships, etc. [4,5]. However, most thermal-spray coatings are porous, layered structures, which have a low bonding strength, easy exfoliation, uneven surface coating density and thickness, poor wear and corrosion resistance, etc. Therefore, in recent years, researchers have actively explored coating remelting treatment technology, especially laser remelting technology, to study the influence of laser remelting technology on the microstructure and properties of coatings. González et al. [6] studied the laser remelting of the $\mathrm{NiCrBSi}$ alloy coating on the surface of a grey cast iron and found that the treated coating was well bonded to the substrate, with almost no pores and cracks. Lei et al. [7] researched the effect of scanning speed on the carbon firber reinforced Ni-based composite and found that the microhardness of a coating could reach up to $405 \mathrm{HV}_{0.2}$ when the speed was $8 \mathrm{~mm} / \mathrm{s}$. Wu et al. [8] 
prepared $\mathrm{NiCrAlY}$ and $\mathrm{NiCrAlY}+\mathrm{Al}_{2} \mathrm{O}_{3}$ coatings by thermal spraying and laser remelting and showed that the coating formed by laser remelting was denser than that formed by thermal spraying, and the holes, vacancies, unmelted particles, and cracks in the coating disappeared. Shi et al. [9] proposed that the addiction of carbon fibers ( $\mathrm{CFs}$ ) could improve the microhardness and tensile strengthen of the nickel based coatings by 1.7 and 3.7 times, respectively. Ma et al. [10] studied the laser remelting of $\mathrm{Ni} 60+50 \mathrm{wt} \% \mathrm{WC}$ cladding to a Q550 steel substrate. This research showed that the remaining WC particles were eliminated after remelting, cracking was reduced, the cladding surface was smooth, the micro-hardness of the remelted area is reduced by $50 \mathrm{HV}_{0.1}$ compared to that formed by laser cladding, and the carbide is assimilated to improve the compactness of the coating.

As it is well-known, the mechanical properties and the crack problems are the most uncontrollable problems for the coatings. Furthermore, there is no doubt that the thermal and mechanical mismatches of the interface caused by the differences of atomic structure, chemical composition, and atomic bonding between the reinforcing coating and substrate are the main reasons for damage to the composite [11-13]. Although the interface structure's influence on the coating structure cannot be accurately described, the microstructure of the coating has a direct effect on the microstructure of the coating in the process of remelting, thereby affecting the performance of the coating [14]. Furthermore, the regulating effect of the remelting process parameters on the interface structural forms is the research focus in this field [15-17].

Therefore, the authors prepared a nano-SiC modified Fe-based Ni/WC composite coating on the surface of 45 steel by plasma spraying and laser remelting and analyzed the bonding interface quality under different laser powers in this study. The microstructure, phase composition, element distribution, and micro-hardness of the interface between the coating and substrate were analyzed to provide a theoretical basis for the application and popularization of laser remelting in the field of thermal spraying.

\section{Experimental Work}

\subsection{Coating Preparation}

The substrate material was a common grade 45 steel; the coating material was a cermet coating produced by Chengdu Zhenxing Metal Powder Co., Ltd. (Chengdu, China) that was made of an iron-based alloy powder (Fe40) and a nickel-based tungsten carbide alloy powder (Ni60 $+35 \mathrm{WC})$ mixed in the ratio of 9:1. The related chemical compositions are shown in Tables 1 and 2.

For plasma spraying, a $0.4 \mathrm{~mm}$ Fe $40+\mathrm{Ni} 60+35 \mathrm{WC}$ cermet coating was applied to the surface of 45 steel using a JP-8000 automatic spray system (TAFA, Shanghai, China). To facilitate microstructural observation, we etched $4 \%$ nitric acid on a small sample section for about $5 \mathrm{~s}$. The Accord- 600 laser remelting equipment produced by Dongguan Aoxing Laser Co., Ltd. (Dongguan, China) was used to perform laser remelting after the nano-SiC preset, and the parameters for controlling the laser remelting process are shown in Table 3. The nano-SiC had a purity of $97 \%$ and an average particle size of $40 \mathrm{~nm}$. In order to ensure that the coating surface had a sufficient absorption rate for the laser during remelting and to avoid splashing and gasification of the nano powder during the remelting process, a certain amount of binder and light-absorbing coating were added to the nano-SiC powder, and fully stirred. After mixing, it was made thick and uniformly coated on the surface of the Fe-based WC coating to a thickness of about $0.1 \mathrm{~mm}$.

The prepared samples were cut into specimens measuring $15 \mathrm{~mm} \times 10 \mathrm{~mm} \times 6 \mathrm{~mm}$ using a wire cutting machine tool: the cross-sections were sequentially polished with 400, 600, 800, 1000, 1200, and 1500 sandpaper, and polished with a polishing solution until a bright mirror effect was reached. To facilitate the microstructural observations, small sample cross-sections were etched with $4 \%$ nitric acid for about $5 \mathrm{~s}$. 
Table 1. Chemical composition of the Fe-based alloy powder Fe40 (wt \%).

\begin{tabular}{ccc}
\hline Element & Content & Measured Value \\
\hline $\mathrm{Ni}$ & $8-12$ & 8.9 \\
$\mathrm{Cr}$ & $15-20$ & 16.4 \\
$\mathrm{~B}$ & $1.5-3$ & 2.1 \\
$\mathrm{Si}$ & $1.5-3$ & 1.9 \\
$\mathrm{C}$ & $<0.5$ & - \\
$\mathrm{Fe}$ & Trace & - \\
\hline
\end{tabular}

Table 2. Chemical composition of nickel tungsten carbide powder Ni60 + 35WC (wt \%).

\begin{tabular}{ccc}
\hline Element & Content & Measured Value \\
\hline $\mathrm{Ni}$ & Trace & - \\
$\mathrm{Cr}$ & $15-20$ & 17.2 \\
$\mathrm{~B}$ & $3.0-4.5$ & 3.1 \\
$\mathrm{Si}$ & $3.5-5$ & 4.1 \\
$\mathrm{C}$ & $0.5-1.1$ & 0.93 \\
$\mathrm{Fe}$ & $\leq 10$ & 9.3 \\
$\mathrm{WC}$ & 35 & 35 \\
\hline
\end{tabular}

Table 3. Parameters governing the laser remelting process.

\begin{tabular}{ccc}
\hline Laser Power $(P / W)$ & $\begin{array}{c}\text { Scanning Speed }(\boldsymbol{V}) \\
(\mathbf{m m} / \mathbf{m i n})\end{array}$ & Spot Diameter $(\boldsymbol{D})(\mathbf{m m})$ \\
\hline 400 & 200 & 1.5 \\
500 & 200 & 1.5 \\
600 & 200 & 1.5 \\
\hline
\end{tabular}

\subsection{Analysis and Characterisation}

The microstructural features of the interface between the coating and the substrate were analysed using a MLA650F field emission scanning electron microscopy (FESEM, FEI, Hillsboro, OR, USA). The distribution of interfacial elements was analyzed by examination of their energy spectra and the phase of the coating was analyzed using an Empyrean X-ray diffraction (XRD) system (PANalytical, Almelo, The Netherlands). Then, the structures and grain sizes of the test sample were calibrated and quantified using Jade software (6.5), respectively. The microhardness was measured at the cross-section of the polished samples with an FM-700 type micro-hardness tester (Fangce Instruments Co., Ltd., Shenzhen, China), under the loading of $1 \mathrm{~kg}$ and a test distance of $0.05 \mathrm{~mm}$ for $10 \mathrm{~s}$. Each test was repeated to give a sample size of $n=3$ before averaging.

\section{Results and Analysis}

\subsection{Analysis of Interface Morphology}

Figure 1 shows the topography of the plasma spray interface and the coating. Generally speaking, the bonding state between the coating and the substrate will directly affect the interfacial bond strength of the coating. The combination of metal matrix and cermet coating mainly includes metallurgical combination, physical combination, diffusion bonding, and the mechanical combination thereof. It can be seen from Figure 1a that the main bonding mode of the plasma spraying interface was mechanical bonding. The interface of the coating contained several large holes and obvious interlayer cracks; it mainly included a solid-solid interface formed between the substrate and the coating layer. Even between the layers in the coating layer, Figure $1 \mathrm{~b}$ shows the plasma spray coating morphology; the main structure of the coating was a typical layered structure, and there was a solid-gas interface in the pores or micro-cracks. 


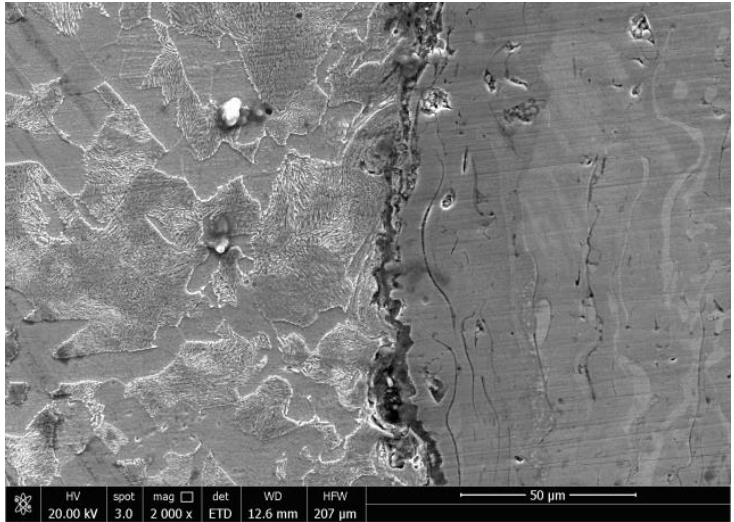

(a)

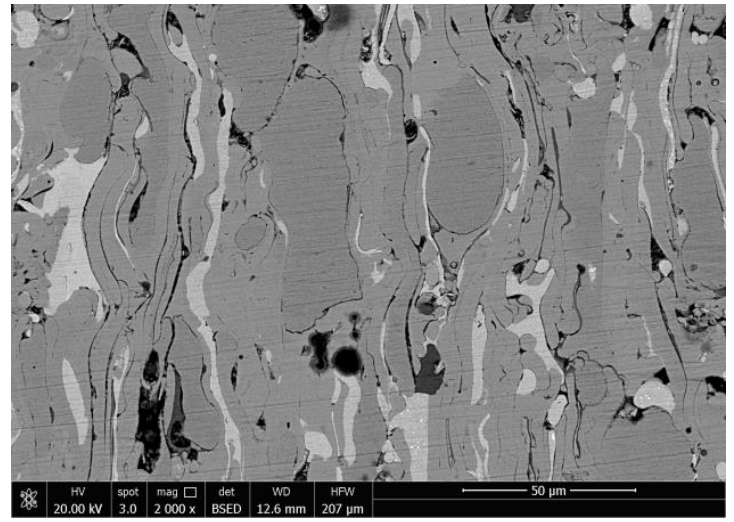

(b)

Figure 1. Interface morphology and cross section morphology of plasma sprayed coatings: (a) interface morphology; (b) coating morphology.

Figure 2a,b shows the effects of different laser power on interface morphology and coating morphology, respectively. It can be seen that nano-SiC particles were evenly distributed on the surface of the coating. Furthermore, the nano-SiC-modified remelted coating was smooth and compact with no fine cracks. Most of the internal defects were eliminated, the coating density was improved, and the cross-sectional area of the coating was larger (by 8000 times). Fine pores (small black spots) were visible, and it appeared reticulated in form. However, there were differences between coatings due to different laser powers. When the laser power was $400 \mathrm{~W}$, the cross-section of the coating "mesh" structure was bulky, and the interface between the coating and the substrate could also produce many similar small holes (A and B, each about $1 \mathrm{~nm}$ in diameter), and the interface profile was wavy. There may be two reasons for this: the laser power was too low, so with the lack of energy, the coating of the refractory phase could not be fully melted in the process of rapid solidification, and the gas could generate micro-pores and produce tiny cracks; second, rapid heating and cooling, under the thermal stress caused by micro-pores affects the structure. At a laser power of $500 \mathrm{~W}$, the coating and the substrate bonding interface had a saw-tooth shape with good metallurgical bonding, small holes inevitably still remain in cross-section of the coating, but the number of holes was reduced and the microstructure of the coatings was finer than that at $400 \mathrm{~W}$. At a laser power of $600 \mathrm{~W}$, the cross-sectional coating was more refined, the corresponding reduction in the number of holes, and the network structure, were similar to the complete "fishbone type" seen previously. In addition, it can be seen from the interface topography that the interface line was an irregular fusion line, not an ideal straight line. The interface area $\mathrm{C}$ was a fine hole: the formation of micro-pores at $\mathrm{A}$ and $\mathrm{B}$ meant that laser remelting and rapid cooling caused some elemental segregation, so that the solidified part of the grain boundary frontier growth was blocked, resulting in tiny holes being generated. Besides, the structure of regions $\mathrm{D}$ and $\mathrm{E}$ was the same as that of the matrix, mainly because the power was too large, and the matrix material and the coating material in the remelting area flow into the liquid metal. Mutual fusion, then rapid cooling, occur after the formation of similar areas at $\mathrm{D}$ and $\mathrm{E}$; therefore, the above analysis shows that a laser power of $500 \mathrm{~W}$ was best when a plasma-sprayed, nano-SiC Fe-based Ni/WC cermet coating was remelted by a laser. 

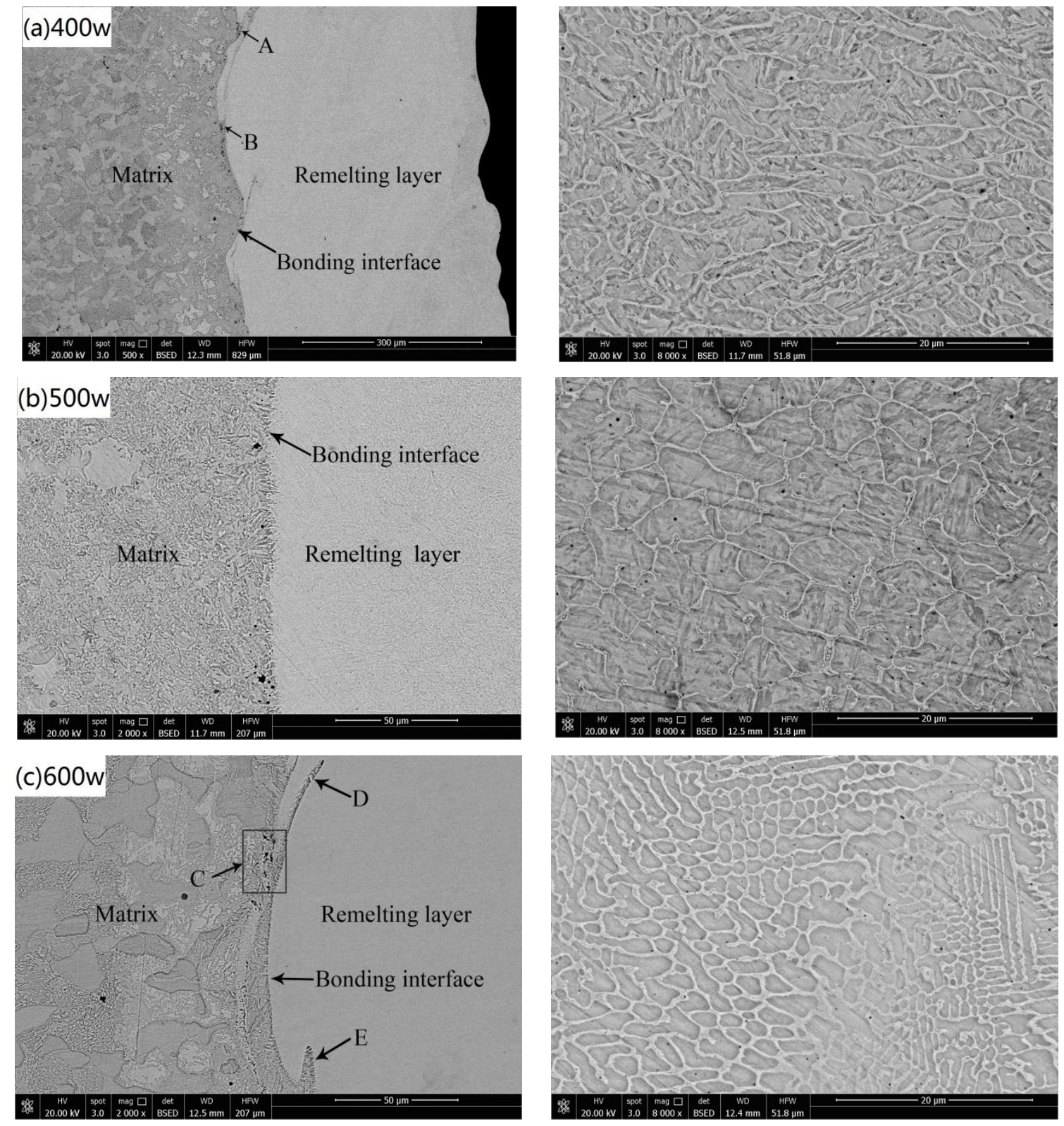

Figure 2. Interface morphology and cross section coating morphology under different powers:

(a) $400 \mathrm{~W}$; (b) $500 \mathrm{~W}$; and (c) $600 \mathrm{~W}$.

\subsection{Phase and Grain Analysis}

Figure 3a shows the X-ray diffraction pattern of the remelted layer under different laser powers. It can be seen that the interface between the matrix and the coating was mainly composed of [Fe,Ni], $\mathrm{Cr}, \mathrm{Fe}_{0.04} \mathrm{Ni}_{0.36}$ compounds and a hard phase. As the laser power increased, the diffraction intensity increased accordingly; by comparison, it can be seen that the microstructure of the substrate and the coating was more complicated at $500 \mathrm{~W}$ and a multi-phase structure was generated, which indicated that the interface bond strength was greater at $500 \mathrm{~W}$. The added nano-SiC was decomposed under the action of a high-energy laser. The decomposed $\mathrm{Si}$ underwent a metallurgical chemical reaction with $\mathrm{Fe}$, $\mathrm{Cr}$, etc. in the original coating to form a hard intermediate phase, enhance the strength, and improve the performance of the coating successfully. The generation of $\mathrm{C}_{0.09} \mathrm{Fe}_{1.91}$ indicated that there was a martensitic phase at the interface of the coating; the appearance of $\mathrm{Cr}$ during laser remelting indicated that some supersaturated solid solution and metal carbide could be produced by increasing the laser 
power, which played the role of a solid solution strengthening and dispersion strengthening in the coating; however, in the process of laser remelting, there was no obvious peak value of WC, and most of the WC was decomposed, with decarburisation seen (i.e., $2 \mathrm{WC}+\mathrm{O}_{2}=\mathrm{W}_{2} \mathrm{C}+\mathrm{CO}_{2}$ ). As the energy of remelting would lead to the substrate melting and undergoing melt flow diffusion into the composite coating, at different laser powers, the input heat energy was not the same, and there were different degrees of dilution, so the composite coating caused decreases in the intensity of the diffraction peaks.
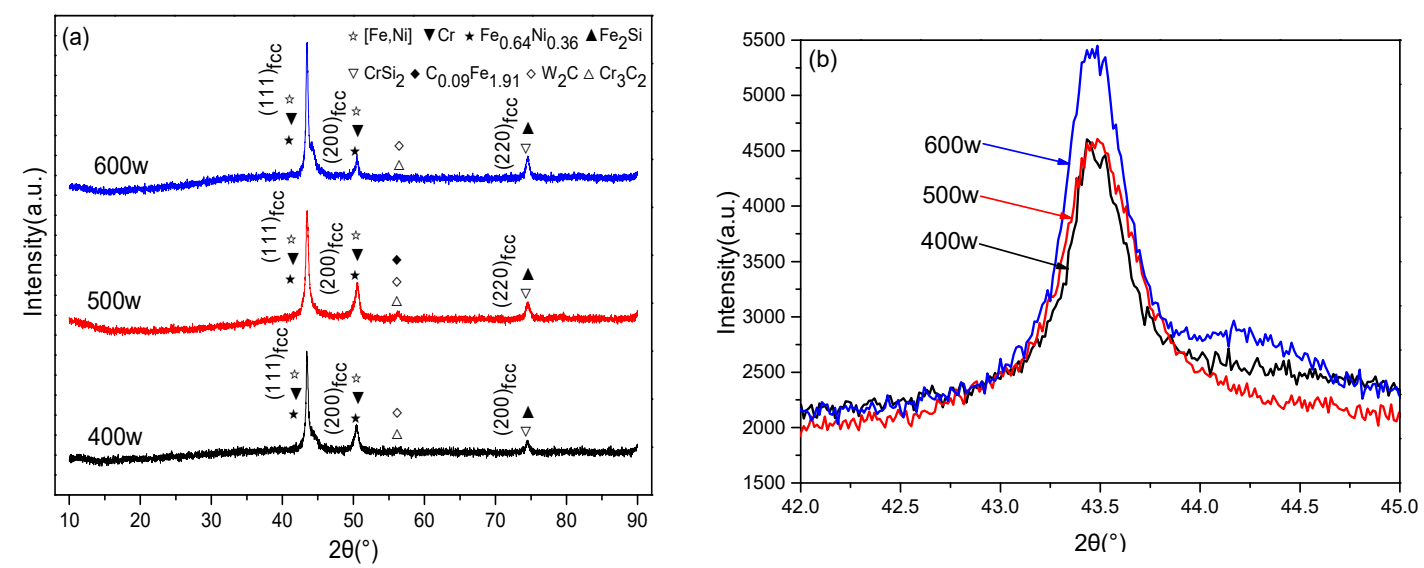

Figure 3. (a) XRD pattern of the remelted layer at $400 \mathrm{~W}, 500 \mathrm{~W}$, and $600 \mathrm{~W}$, and (b) first primary peak.

In addition, Jade software was used to remove the broadening effect of the instrument. Figure 3a shows that the lattice parameters of the fcc phase at 400, 500, and $600 \mathrm{~W}$ were $0.2550,0.2566$, and $0.2568 \mathrm{~nm}$, respectively, which meant that all the grain sizes of the fcc phase precipitated under the three different powers were less than $10 \mathrm{~nm}$. Calculated by the Williamson-Hall formula (Equation (1)) [18], we can get that the lattice distortions reached $0.22 \%, 0.28 \%$, and $0.3 \%$, respectively. These shows that the greater the power, the more obvious the microscopic stress caused by lattice distortion. Therefore, the strength and hardness of the coatings were improved by the refinement of grain size and the hindering of dislocation slip deformation. Properties of nano-SiC particles with a large specific surface area, containing the number of atoms relative to the surface, more easily in the process of coating remelting have played an important role in heterogeneous nucleation core, and this slowed down the remelting layer medium axis crystal and columnar crystal growth, inhibiting the abnormal grow up. It has been proved that the broadening effect and microstrain caused by grain refinement are respectively in accordance with Lorentz and Gauss functions [19]. To observe the effect of laser power on the grain refinement more objectively, the comparison of the broadening phenomenon of the first main peak ( $42-45^{\circ}$ diffraction angle) is shown in Figure $3 \mathrm{~b}$; the higher the power, the greater the half-peak height (FWHM), and the smaller the grain size, which is consistent with previous results. Grain refinement can be explained as follows: in a laser remelting process, providing a lot of heat, then rapid cooling to the crystallization process, causes significant sub-cooling, and where the critical nucleation size is very small, this inhibits nano-SiC particles growth, thus generating a fine-grain remelting layer. Here:

$$
\frac{\beta_{h k l}^{2}}{\operatorname{tg}^{2} \theta_{h k l}}=\frac{\lambda \beta_{h k l}}{d_{h k l} \operatorname{tg} \theta_{h k l} \sin \theta_{h k l}}+4\left(\varepsilon^{2}{ }_{h k l}\right)^{1 / 2}
$$

where $\theta_{h k l}$ is the diffraction angle, $\lambda$ is $\mathrm{Cu}_{h k l}$ and represents wavelength, $d_{h k l}$ is the grain size in the vertical direction along the plane $(h, k, l)$, and $\left(\varepsilon^{2}{ }_{h k l}\right)^{1 / 2}$ is the average atomic microscopic distortion in the vertical direction along the crystal plane $(h, k, l)$. 


\subsection{Analysis of the Coating Interface Elements}

Figure 4 shows the scanning results of elements for different laser powers obtained using a spectrometer (EDS). From the figure, we can find that the elements show a similar evolution law. Fe enrichment phenomenon was the most obvious and it could reach as much as $68.03 \%$ at $500 \mathrm{~W}$. Even though other elements, such as $\mathrm{C}, \mathrm{Cr}$, and $\mathrm{Ni}$, were lower, they also played an important role in improving the strength and hardness of the remelting layer by forming a substitutional solid solution of $[\mathrm{Fe}, \mathrm{Ni}]$ and a hard phase strengthening phenomenon such as $\mathrm{Cr}_{7} \mathrm{C}_{3}$ and $\mathrm{Fe}_{0.04} \mathrm{Ni}_{0.36}$ compounds. According to the analysis, due to the addition of nano-SiC particles, the grain refinement and the solid-liquid shrinkage in the molten pool were enhanced, and the heat transfer capability of the coating surface to the inside during remelting was improved, resulting in the coating being combined with the matrix material. The temperature at the interface increased and a more pronounced diffusion occurred between the atoms of the elements. It was precisely because of the interdiffusion of these atoms, depending on the substrate being a ready-made surface for joint crystallisation [20] in the interface to form a common grain, that the remelting layer and the matrix between were combined metallurgically. Only a small amount of Si was found on the surface coating. This was because the added nano-SiC particles decomposed during laser remelting, which indicated that trace amounts of $\mathrm{Si}$ did not destroy the microstructure of the 45 steel matrix. Not only that, Si could also adsorb oxygen in the coating well and generate a low melting point and good fluidity of $\mathrm{SiO}_{2}$, and together with other inclusions, form a slag floating, resulting in a continuous compact and less porous coating. Research shows that residual particles, seen after laser remelting, exert a dislocation pinning effect on metal ceramic coatings, and thus avoid the generation of some micro-defects (such as micro-cracks), which improves the fracture toughness of such materials [21,22]. Therefore, the diffusion of trace $\mathrm{Si}$ atoms was beneficial to the improvement of the bonding properties between the coating and substrate.
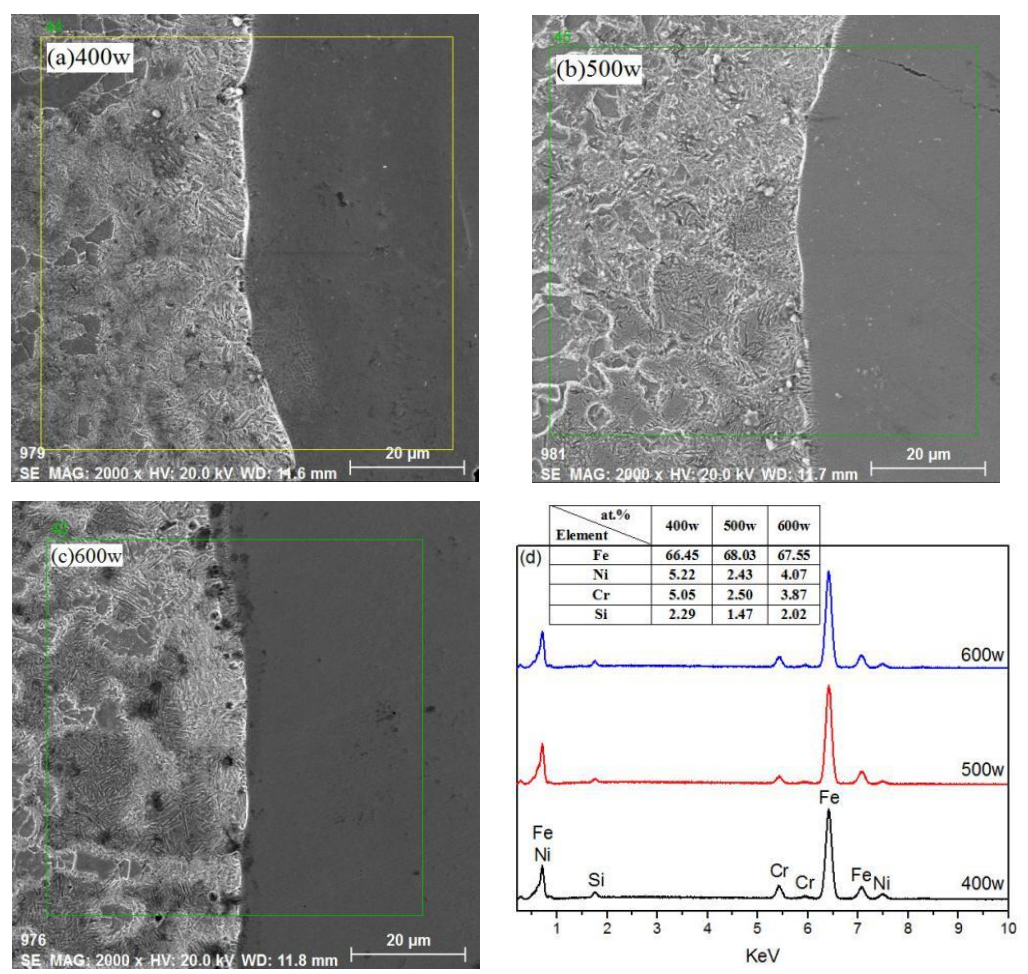

Figure 4. Scans taken after application of (a) $400 \mathrm{~W}$, (b) $500 \mathrm{~W}$, and (c) $600 \mathrm{~W}$; (d) scan results to the interface.

Figure 5 shows the result of laser remelting at $500 \mathrm{~W}$ in the form of an interface line scan: the scanning line length was $50 \mu \mathrm{m}$, from where it can be seen that the $\mathrm{Ni}, \mathrm{Cr}$, and $\mathrm{Si}$ elements 
were mainly enriched in the remelting layer and the distribution thereof was relatively uniform. Furthermore, the content of these three elements gradually increased from matrix to remelting layer, and showed a continuous gradient distribution. This indicated that the $\mathrm{Ni}, \mathrm{Cr}$, and $\mathrm{Si}$ elements mainly produced a certain diffusion and gradient distribution from the remelting layer to the matrix, which evinced good metallurgical bonding. Instead, the content of Fe mainly diffused from the substrate to the remelted layer during the unsteady diffusion process. The elemental $\mathrm{C}$ was also distributed more evenly in the remelted layer, but its concentration fluctuated greatly in the matrix, which indicated that the distribution was not very uniform in the matrix. In fact, according to the Arrehenius formula (Equation (2)), the diffusion coefficient $D$ increases exponentially with the temperature $T$. The lower the temperature, the smaller the atomic diffusion capacity, and the more the atomic diffusion becomes inactive. Due to the existence of the temperature gradient caused by the rapid solidification, the contents show a continuous gradient distribution.

$$
D=D_{0} \exp \left(-\frac{Q}{R T}\right)
$$

where $D_{0}$ is the diffusion constant; $R$ is the gas constant, $8.314 \mathrm{~J} \cdot \mathrm{mol}^{-1} \cdot \mathrm{K}^{-1} ; Q$ is the diffusion activation energy, and $T$ is temperature.

Figure 6 shows the plane scan analysis results (from Figure 5a): it can be seen that the $\mathrm{Cr}, \mathrm{Ni}$, and $\mathrm{Si}$ in the coating were brighter and therefore account for larger volumetric proportions of the total. The Fe was mainly seen as bright features in the matrix. These results were consistent with the results of line-scan analysis. From the above three types of EDS scanning analysis, it is known that the metal elements $\mathrm{Fe}, \mathrm{Ni}, \mathrm{Cr}$, and $\mathrm{Si}$ underwent diffusion, and there was a certain metallurgical bonding present between coating and matrix.

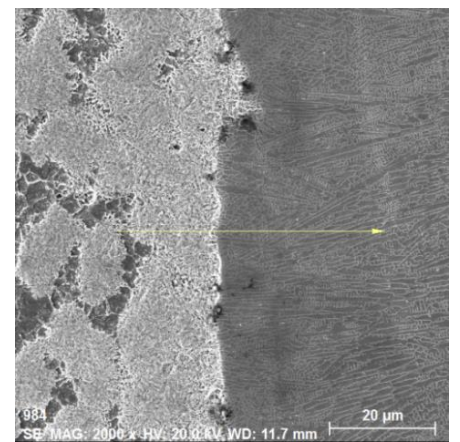

(a)

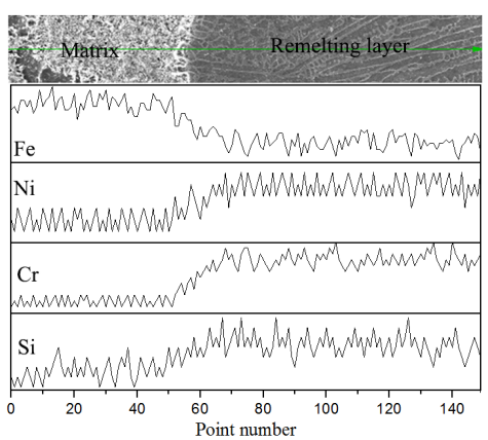

(b)

Figure 5. Line scan results: interface after laser remelting at $500 \mathrm{~W}$. (a) Line scanning; (b) Line scan results.

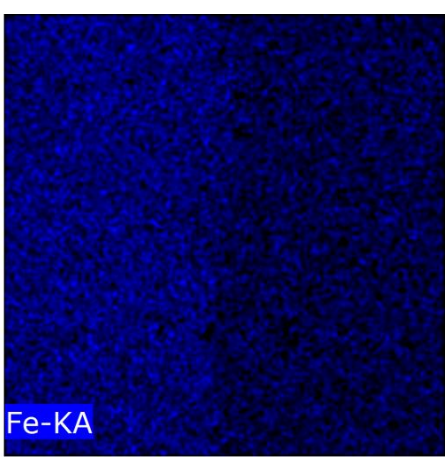

(a)

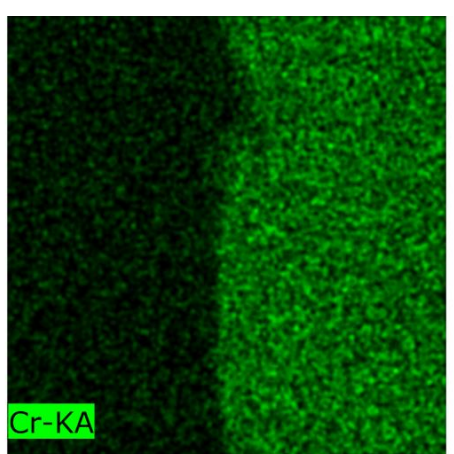

(b)

Figure 6. Cont. 


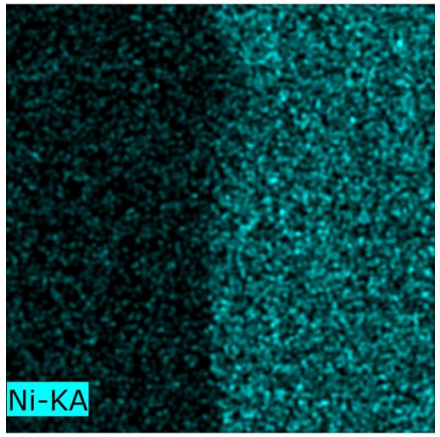

(c)

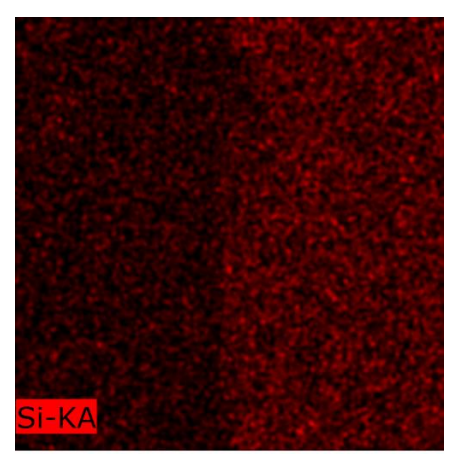

(d)

Figure 6. Plane scan results: interface after laser remelting at $500 \mathrm{~W}$ : (a) Fe-KA; (b) Cr-KA; (c) Ni-KA; and (d) Si-KA.

\subsection{Micro-Hardness Analysis}

Figure 7 shows the micro-hardness curve under different laser powers. It can be seen that laser remelting and the addition of nano-SiC particles have greatly improved the microhardness of coatings. The micro-hardness increased with depth from the bonding interface to the coating surface. With increasing laser power, the hardness of the laser remelting nano-SiC modified Fe-based Ni/WC composite coatings increased in general terms and the maximum hardness increased by $51 \%$. Analysts believe that the reasons can be attributed to the interaction between the elements $\mathrm{Ni}, \mathrm{Cr}, \mathrm{Fe}, \mathrm{Si}, \mathrm{C}$, and other elements in the remelting layer during the rapid solidification process. In addition, according to the Hall-Petch formula (Equation (3)) [23], the smaller the grain size $d$, the higher the hardness of the material $H$. After laser remelting, the newly-formed hard phase interacts with the fine parts of the resulting dense microstructure formed by rapid melting. The nano-sized $\mathrm{SiC}$ particles serve as the core of the heterogeneous nucleation to refine the grains on the one hand, and promote the formation of a hard intermediate phase in the coating on the other hand. Therefore, the addition of nano-SiC particles improved the microhardness of the coating greatly. The matrix was also partially melted, and, at the same time, the results of the grain analysis were also verified.

$$
H=H_{0}+k d^{-\frac{1}{2}}
$$

where $H$ is the measured hardness, $H_{0}$ is the intrinsic value of hardness, $k$ is a material-related parameter, and $d$ is the average grain diameter.
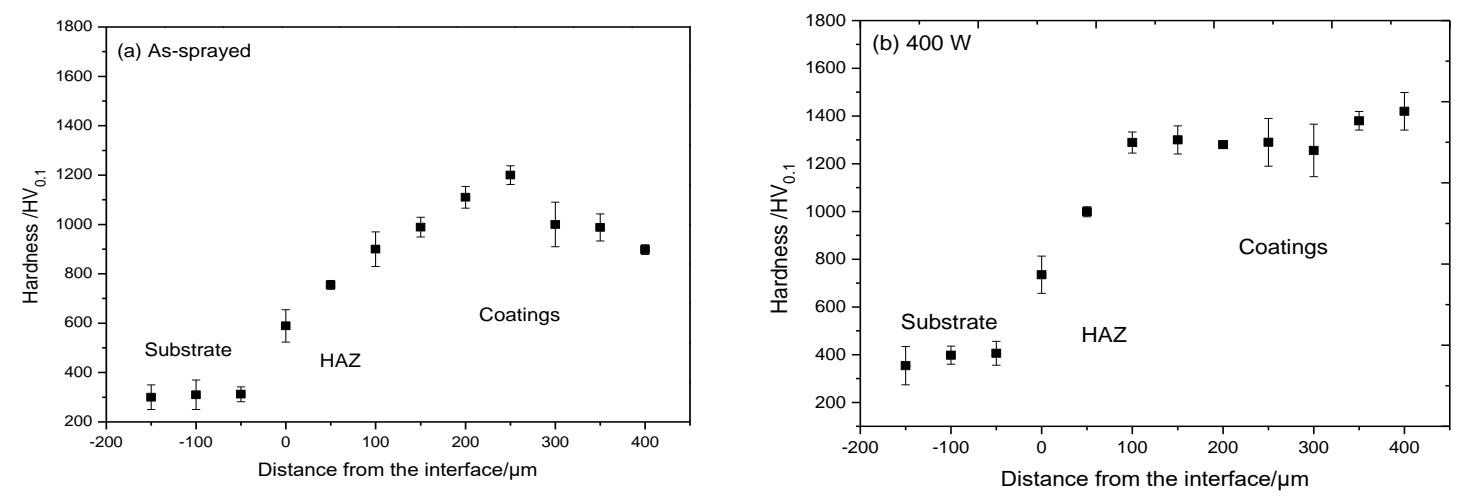

Figure 7. Cont. 

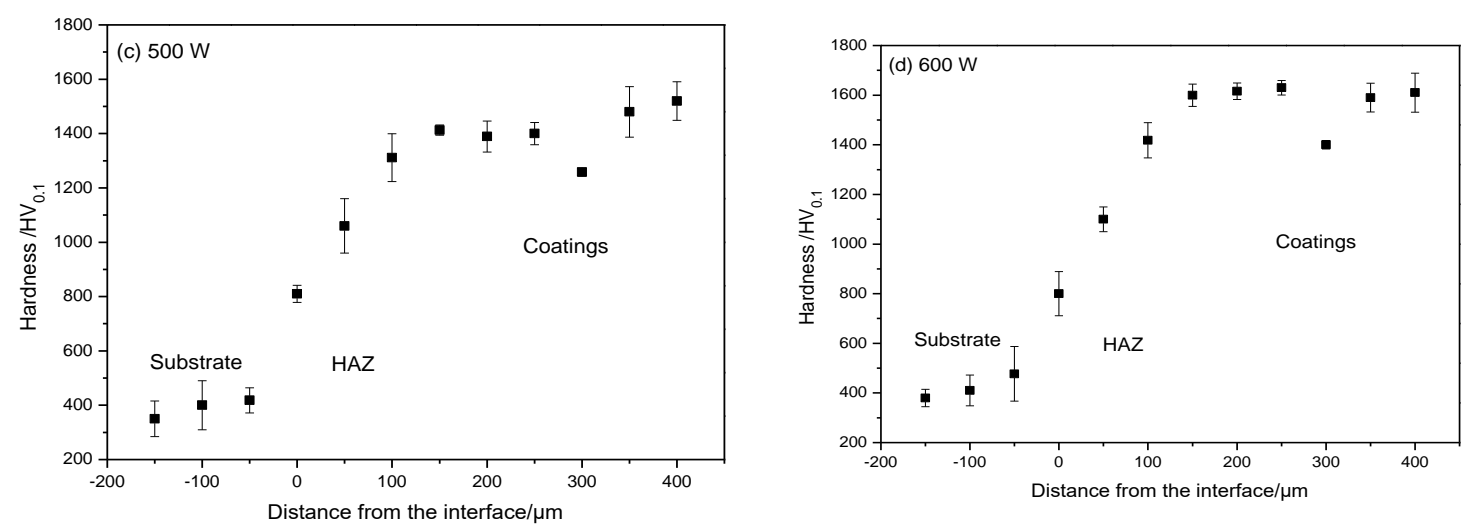

Figure 7. Micro-hardness changes through the cross-section: (a) as-sprayed; (b) 400 W; (c) 500 W; and (d) $600 \mathrm{~W}$.

\section{Conclusions}

- The interface of the plasma spraying coating contained several large holes and obvious interlayer cracks. A layered structure and mechanical bonding were the main features.

- After laser remelting, the nano-SiC modified remelting coating was smooth and dense without fine cracks. The interfacial metallurgical bonding, caused by the interdiffusion of metal elements $\mathrm{Fe}, \mathrm{Ni}, \mathrm{Cr}$, and $\mathrm{Si}$, reached the best effect at $500 \mathrm{~W}$. The nano-SiC modified remelting layer was mainly composed of [Fe,Ni], $\mathrm{Cr}, \mathrm{Fe}_{0.04} \mathrm{Ni}_{0.36}$ phases.

- The nano-sized SiC particles served as the core of the heterogeneous nucleation to refine the grains on the one hand, and promote the formation of a hard intermediate phase in the coating on the other hand. Therefore, the addition of nano-SiC particles improved the microhardness of the coating greatly. With increasing laser power, the hardness increased in general terms and the maximum hardness increased by $51 \%$.

- With the increase of power, the average grain size and half-peak height (FWHM) became smaller and wider, respectively. The greater the laser power, the lesser the corresponding number of holes. When the laser power was $600 \mathrm{~W}$, a complete "fishbone type" of network structure could be found.

Author Contributions: Conceptualization, Y.Z. and W.H.; Methodology, H.D.; Software, P.L.; Validation, Y.Z., W.H. and H.D.; Formal Analysis, P.L.; Investigation, Y.Z. Resources, W.H.; Data Curation, H.D.; Writing-Original Draft Preparation, P.L.; Writing-Review \& Editing, Y.Z.; Visualization, W.H.; Supervision, H.D.; Project Administration, P.L.; Funding Acquisition, Y.Z.

Funding: The research was funded by National Natural Science Foundation of China (No. 51565017), Tribology technology and application of high end bearings-National Open Project for local joint engineering laboratory (No. 201713), Natural Science Foundation of Jiangxi province (No. 2012BAB206026), and Jiangxi Provincial Education Department (No. GJJ14424).

Acknowledgments: Thanks to Engineering Research Institute of Jiangxi University of Science and Technology for supporting the experiment.

Conflicts of Interest: The authors declare no conflict of interest.

\section{References}

1. Zhang, F.; He, J.; Chen, K.; Qin, Y.; Li, C.; Yin, F. Microstructure evolution and mechanical properties of TiCN-Cr nano/micro composite coatings prepared by reactive plasma spraying. Appl. Surf. Sci. 2018, 428, 905-914. [CrossRef]

2. Nishinoiri, S.; Enoki, M.; Tomita, K. In situ monitoring of microfracture during plasma spray coating by laser AE technique. Sci. Technol. Adv. Mater. 2003, 4, 623-631. [CrossRef] 
3. Gao, Y.; Jie, M.; Liu, Y. Mechanical properties of $\mathrm{Al}_{2} \mathrm{O}_{3}$ ceramic coatings prepared by plasma spraying on magnesium alloy. Surf. Coat. Technol. 2017, 315, 214-219. [CrossRef]

4. Yumiba, N. Trend of thermal spray industry and applications. Therm. Spray Technol. 2010, 3, 452-457.

5. Yasuo, N.; Nagai, M. Thermal spray coating on conductor rolls in electroplating line. Baosteel Tech. Res. 2010, 4,41 .

6. González, R.; Cadenas, M.; Fernández, R.; Cortizo, J.L.; Rodríguez, E. Wear behaviour of flame sprayed NiCrBSi coating remelted by flame or by laser. Wear 2007, 262, 301-307. [CrossRef]

7. Lei, J.; Shi, C.; Zhou, S.; Gu, Z.; Zhang, L. Enhanced corrosion and wear resistance properties of carbon fiber reinforced Ni-based composite coating by laser cladding. Surf. Coat. Technol. 2018, 334, 274-285. [CrossRef]

8. Wu, Y.; Zhang, G.; Feng, Z.; Zhang, B.; Liang, Y.; Liu, F. Oxidation behavior of laser remelted plasma sprayed NiCrAlY and NiCrAlY- $\mathrm{Al}_{2} \mathrm{O}_{3}$ coatings. Surf. Coat. Technol. 2001, 138, 56-60. [CrossRef]

9. Shi, C.; Lei, J.; Zhou, S.; Dai, X.; Zhang, L. Microstructure and mechanical properties of carbon fibers strengthened Ni-based coatings by laser cladding: The effect of carbon fiber contents. J. Alloys Compd. 2018, 744, 146-155. [CrossRef]

10. Ma, Q.; Li, Y.; Wang, J.; Liu, K. Homogenization of carbides in Ni60/WC composite coatings made by fiber laser remelting. Mater. Manuf. Processes 2015, 30, 1417-1424.

11. Yu, P.; Zhang, L.; Zhang, W.; Das, J.; Kim, K.B.; Eckert, J. Interfacial reaction during the fabrication of $\mathrm{Ni}_{60} \mathrm{Nb}_{40}$ metallic glass particles-reinforced Al based MMCs. Mater. Sci. Eng. A 2007, 444, 206-213. [CrossRef]

12. Liu, W.; Sheng, T.; Kong, D. Effects of laser remelting on surface-interface morphologies, bonding modes and corrosion performances of arc-sprayed Al coating. Anti-Corros. Methods Mater. 2017, 64, 43-51.

13. Movchan, B.A.; Marinski, G.S. Gradient protective coatings of different application produced by EB-PVD. Surf. Coat. Technol. 1998, 100-101, 309-315. [CrossRef]

14. Gao, X.; Tian, Z.; Liu, Z.; Shen, L. Interface characteristics of $\mathrm{Al}_{2} \mathrm{O}_{3}-13 \% \mathrm{TiO}_{2}$ ceramic coatings prepared by laser cladding. Trans. Nonferrous Met. Soc. China 2012, 22, 2498-2503. [CrossRef]

15. Jia, Z.; Li, J.; Liu, L.; Liu, Y.; Wang, Y.; Li, H. Influence and application of laser parameters on unit of H13 steel by laser remelting process. Int. J. Adv. Manuf. Technol. 2015, 79, 551-568. [CrossRef]

16. Ciubotariu, C.-R.; Frunzăverde, D.; Mărginean, G.; Șerban, V.-A.; Bîrdeanu, A.-V. Optimization of the laser remelting process for HVOF-sprayed Stellite 6 wear resistant coatings. Opt. Laser Technol. 2016, 77, 98-103. [CrossRef]

17. Wang, Y.; Li, C.; Guo, L.; Tian, W. Laser remelting of plasma sprayed nanostructured $\mathrm{Al}_{2} \mathrm{O}_{3}-\mathrm{TiO}_{2}$ coatings at different laser power. Surf. Coat. Technol. 2010, 204, 3559-3566. [CrossRef]

18. Klug, H.P.; Alexander, L.E. X-ray Diffraction Procedures for Polycrystalline and Amorphous Materials; Wiley: Hoboken, NJ, USA, 1974.

19. Ungár, T.; Langford, J.I.; Cernik, R.J.; Vörös, G.; Pflaumer, R.; Oszlányi, G.; Kovács, I. Microbeam X-ray diffraction studies of structural properties of polycrystalline metals by means of synchrotron radiation. Mater. Sci. Eng. A 1998, 247, 81-87. [CrossRef]

20. Zhang, W. Welding Metallurgy; Machinery Industry Press: Beijing, China, 1997; pp. 116-127. (In Chinese)

21. Gell, M.; Jordan, E.H.; Sohn, Y.H.; Goberman, D.; Shaw, L.; Xiao, T. Development and implementation of plasma sprayed nanostructured ceramic coatings. Surf. Coat. Technol. 2001, 146-147, 48-54. [CrossRef]

22. Lima, R.S.; Kucuk, A.; Berndt, C.C. Integrity of nanostructured partially stabilized zirconia after plasma spray processing. Mater. Sci. Eng. A 2001, 313, 75-82. [CrossRef]

23. Anderson, P.M.; Li, C. Hall-petch relations for multilayered materials. Nanostruct. Mater. 1995, 5, 349-362. [CrossRef]

(C) 2018 by the authors. Licensee MDPI, Basel, Switzerland. This article is an open access article distributed under the terms and conditions of the Creative Commons Attribution (CC BY) license (http:/ / creativecommons.org/licenses/by/4.0/). 